\title{
Familial summer-type hypersensitivity pneumonitis in Japan: two case reports and review of the literature
}

\author{
Akira Nakajima ${ }^{1}$, Takeshi Saraya ${ }^{1 *}$, Takeshi Mori ${ }^{2}$, Reiko Ikeda ${ }^{3}$, Takashi Sugita ${ }^{3}$, Takayasu Watanabe ${ }^{1}$, \\ Masachika Fujiwara ${ }^{4}$, Hajime Takizawa ${ }^{1}$ and Hajime Goto ${ }^{1}$
}

\begin{abstract}
Background: Hypersensitivity pneumonitis is defined as an allergic lung disease that occurs in response to inhalation of fungal antigens, bacterial antigens, chemicals, dusts, or animal proteins. The incidence of summer-type hypersensitivity pneumonitis is higher in the summer season, especially in Japan, due to the influence of the hot and humid environment and the common style of wood house or old concrete condominiums.

Case presentation: The present report describes a case of a middle-aged married couple who lived in the same house and who simultaneously suffered from summer-type hypersensitivity pneumonitis. This report analyzes these two cases in terms of environmental research and its microbiological, radiological, and pathological aspects. This case report is followed by a review of family occurrences of summer-type hypersensitivity pneumonitis from 22 studies with a total of 49 patients (including the two present cases) in Japan.

Conclusion: Summer-type hypersensitivity pneumonitis may be unrecognized and misdiagnosed as pneumonia or other respiratory diseases. A greater understanding of the clinical, pathologic, and environmental features of summer-type hypersensitivity pneumonitis might help improve diagnosis and delivery of appropriate management for this condition.
\end{abstract}

Keywords: Familial summer-type hypersensitivity pneumonitis, Climate, Geography, Trichosporon species, Environmental factor

\section{Background}

Summer-type hypersensitivity pneumonitis (SHP) is a form of hypersensitivity pneumonitis caused by inhalation of Trichosporon asahii or mucoides during a hot and humid summer season. SHP has been reported in Japan since $1973[1,2]$ and occasionally familial SHP has been described. However, no study has performed a review of the relevant literature so far, and the largest study described by Ando et al. did not clarify the detail of clinical findings associated with familial SHP [1]. Herein, we present two cases of familial SHP and a review of 49 patients in Japan.

\footnotetext{
* Correspondence: sara@yd5.so-net.ne.jp

${ }^{1}$ Department of Respiratory Medicine, Kyorin University School of Medicine, 6-20-2 Shinkawa, 181-8611, Mitaka City, Tokyo, Japan

Full list of author information is available at the end of the article
}

\section{Case presentation}

A 58-year-old married woman was admitted to our hospital in August 2012 with a chief complaint of persistent fever $\left(38^{\circ} \mathrm{C}\right)$, gradually progressive dyspnea on effort, and productive cough for over 1 month. She noticed that her symptoms recurred whenever she stayed in her house, but disappeared when she was outdoors. She had no remarkable medical history. She was a current smoker with a history of 10 pack-years and worked as a caregiver. Her vital signs were as follows: blood pressure of 108/70 $\mathrm{mmHg}$, pulse rate of 89 beats/ minute, temperature of $37.7^{\circ} \mathrm{C}$, respiratory rate of 20 breaths per minute, and oxygen saturation of $89 \%$ at room air. Physical examination was normal except for inspiratory late crackles in all lung fields bilaterally. Chest $\mathrm{x}$-ray (Figure 1A) showed mild infiltration, predominantly in the middle to lower lung fields, with

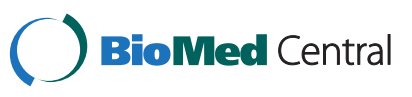



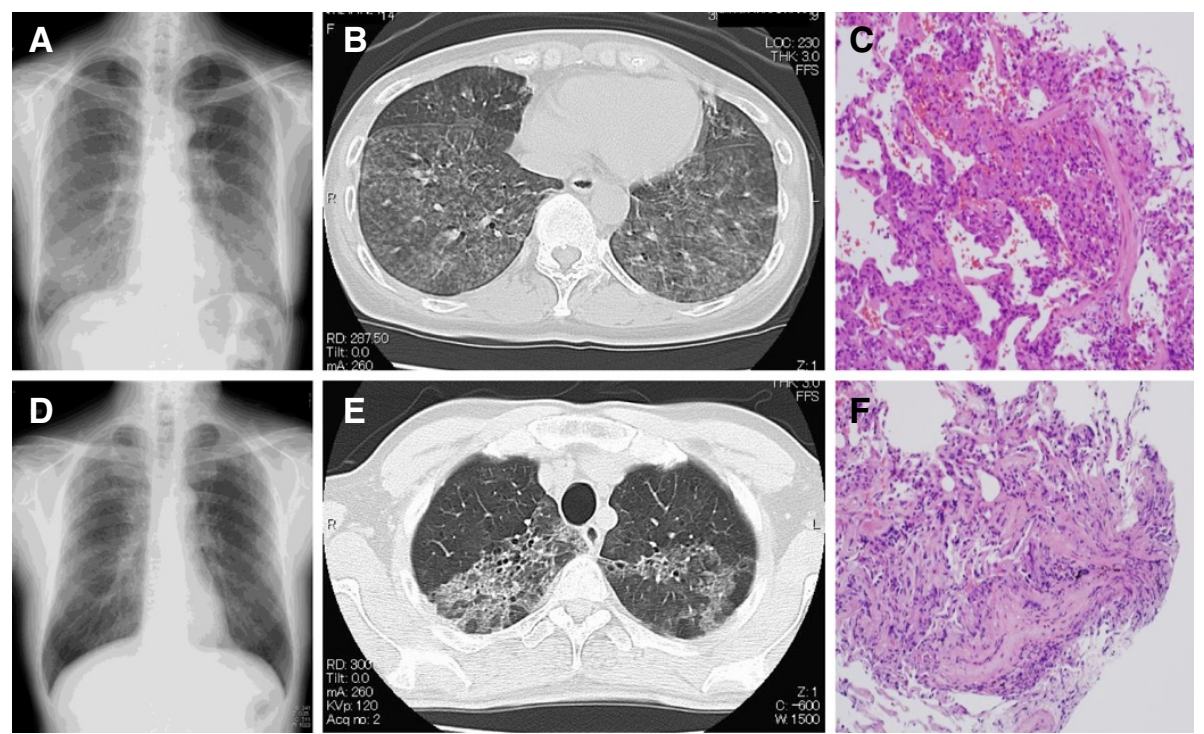

Figure 1 Radiological and pathological assessment for two patients. (wife; A, B, and C): Chest x-ray on the day of admission shows mild infiltrates predominantly in the middle to lower lung fields with multiple scattered nodular lesions (Panel A). Thoracic CT (computed tomography) taken on the same day confirms that these lesions correspond to ground-glass opacities and abundant centrilobular nodules, predominantly located in the bilateral lower lobes (Panel B). Specimens obtained from transbronchial lung biopsy (TBLB) demonstrate organization within the peribronchial area with alveolitis, suggesting transbronchial spread (Panel C). (husband; D, E, and F): Chest X-ray (Panel D) and thoracic CT (Panel E) show ground glass opacities in the upper lungs on both sides. The specimens obtained from TBLB at his local hospital reveals organizing tissue within the peribronchial area with alveolitis, suggesting transbronchial spread (Panel F).

multiple scattered nodular lesions. Thoracic computed tomography (CT) (Figure 1B) revealed ground-glass opacities and abundant centrilobular nodules throughout both lungs, especially in bilateral lower lobes. Laboratory examination showed elevation of lactase dehydrogenase (291 IU/L), C-reactive protein $(4.2 \mathrm{mg} / \mathrm{dL})$, Krebs von den Lungen-6 (1270 IU/L), and surfactant protein D (135 IU/L) (Table 1). Serum anti-Trichosporon asahii antibody was positive by enzyme immunoassay (1.91), and biopsied specimens obtained from transbronchial lung biopsy (TBLB) showed organization within the peribronchial area, with alveolitis accompanying lymphocytic infiltration (Figure 1C), suggesting transbronchial spread. Based on these data, she was diagnosed with SHP. Her chief complaints and hypoxemia resolved spontaneously by the second hospital day, and she was discharged on the fifth hospital day to her home. Two weeks later, she was re-admitted to our hospital with a diagnosis of recurrent SHP. She was subsequently treated with oral prednisolone $(0.8 \mathrm{mg} / \mathrm{kg} /$ day $)$. After cleaning up her house with disinfectant and re-covering the floor, she was discharged again on the eighth hospital day with complete resolution of her symptoms. Human leukocyte antigen (HLA) typing showed DR4, A11, A31, B54, B62, DQ4, and DQ8.

The same patient's husband was a 63-year-old previously healthy man who was admitted to his local hospital with chief complaints of productive cough, dyspnea on effort, and fever of $38^{\circ} \mathrm{C}$ lasting for a few weeks from the beginning of August 2012. He had a smoking history of 25 pack-years and was diagnosed with chronic obstructive pulmonary disease a few years previously. He worked as a stage director and had been in good health until then. The specimens obtained by TBLB (Figure 1F) performed at his local hospital showed organizing tissue within peribronchial area with alveolitis, suggesting bronchial spread. He was tentatively diagnosed with atypical pneumonia and was treated with antibiotics. His symptoms completely resolved within a week, and he was discharged to his home. However, on the day of discharge, 3 hours after returning his home, his symptoms recurred and he presented to our hospital. Initial examination indicated that he was quite ill; his vital signs showed a temperature of $38^{\circ} \mathrm{C}$, and oxygen saturation has dropped to about $80 \%$ at room air. His physical examination showed inspiratory late crackles in the bilateral upper to middle lung fields. Chest $\mathrm{x}$-ray (Figure 1D) and thoracic CT (Figure 1E) showed ground glass opacities in the upper lungs bilaterally. Based on his medical history together with the fact that his wife had already been diagnosed with SHP at the same time, he was diagnosed with SHP. This was confirmed by positive result of serum antiTrichosporon asahii antibody on enzyme immunoassay (1.21), and he was successfully discharged to his son's house on the seventh hospital day with no treatment. His HLA typing showed DR8, A2, A26, B35, B55, and DQ4. 
Table 149 Cases of familial summer type hypersensitivity pneumonitis reported in Japan

\begin{tabular}{|c|c|c|c|c|c|c|c|c|c|c|}
\hline Year & Age & Sex & Season & Smoking history & Tricosporon antibody & Respiratory failure & Steroid therapy & Move & Relapse & Ref \\
\hline \multirow[t]{2}{*}{1982} & 43 & $\mathrm{~F}$ & 7 & N.D & N.D & -- & + & -- & + & 5 \\
\hline & 18 & M & 8 & N.D & N.D & -- & + & -- & -- & 5 \\
\hline \multirow[t]{2}{*}{1984} & 39 & $\mathrm{~F}$ & 8 & N.D & N.D & + & -- & -- & -- & 5 \\
\hline & 12 & M & 8 & N.D & N.D & + & + & -- & -- & 5 \\
\hline \multirow[t]{3}{*}{1985} & 45 & M & 8 & N.D & N.D & + & -- & -- & -- & 5 \\
\hline & 40 & $\mathrm{~F}$ & 8 & N.D & N.D & + & + & -- & -- & 5 \\
\hline & 15 & M & 8 & N.D & N.D & + & -- & -- & -- & 5 \\
\hline \multirow[t]{3}{*}{1987} & 42 & $\mathrm{~F}$ & 8 & + & N.D & -- & -- & -- & N.D & 5 \\
\hline & 41 & $M$ & 7 & + & N.D & + & -- & -- & N.D & 5 \\
\hline & 19 & $\mathrm{~F}$ & 8 & + & N.D & + & + & -- & N.D & 5 \\
\hline \multirow[t]{2}{*}{1990} & 59 & $M$ & 8 & + & N.D & N.D & + & -- & -- & 5 \\
\hline & 57 & $\mathrm{~F}$ & 8 & -- & + & + & + & -- & + & 5 \\
\hline \multirow[t]{2}{*}{1992} & 35 & $\mathrm{~F}$ & 7 & N.D & + & N.D & -- & + & -- & 5 \\
\hline & 14 & $\mathrm{~F}$ & 8 & -- & + & -- & -- & + & -- & 5 \\
\hline \multirow[t]{2}{*}{1994} & 36 & $\mathrm{~F}$ & 8 & N.D & N.D & + & -- & + & -- & 5 \\
\hline & 8 & $\mathrm{~F}$ & 9 & -- & N.D & + & + & + & -- & 5 \\
\hline \multirow[t]{3}{*}{1996} & 39 & $M$ & 9 & + & -- & -- & + & -- & + & 5 \\
\hline & 38 & $\mathrm{~F}$ & 9 & -- & + & -- & + & -- & + & 5 \\
\hline & 15 & F & 8 & -- & + & + & + & -- & + & 5 \\
\hline \multirow[t]{2}{*}{1997} & 36 & $\mathrm{~F}$ & 8 & N.D & + & + & + & -- & -- & 5 \\
\hline & 13 & $M$ & 8 & -- & + & + & + & -- & -- & 5 \\
\hline \multirow[t]{2}{*}{1997} & 63 & $\mathrm{~F}$ & 6 & N.D & -- & -- & -- & N.D & N.D & 5 \\
\hline & 65 & $M$ & 7 & N.D & -- & -- & -- & N.D & N.D & 5 \\
\hline \multirow[t]{2}{*}{1998} & 43 & $\mathrm{~F}$ & N.D & - & N.D & N.D & + & - & + & 5 \\
\hline & 14 & $M$ & 8 & -- & + & + & -- & -- & -- & 5 \\
\hline \multirow[t]{2}{*}{2000} & 65 & $M$ & 8 & + & + & + & -- & -- & -- & 6 \\
\hline & 2 & $M$ & 9 & -- & + & N.D & -- & + & -- & 6 \\
\hline \multirow[t]{2}{*}{2001} & 35 & F & 5 & + & + & -- & -- & -- & -- & 5 \\
\hline & 9 & F & 5 & -- & + & + & -- & -- & -- & 5 \\
\hline \multirow[t]{2}{*}{2002} & 57 & $\mathrm{~F}$ & 8 & -- & + & -- & + & -- & + & 5 \\
\hline & 57 & $M$ & 8 & -- & + & + & + & -- & + & 5 \\
\hline \multirow[t]{2}{*}{2003} & 24 & $M$ & 8 & -- & + & -- & -- & + & -- & 5 \\
\hline & 24 & $M$ & 11 & + & + & -- & -- & + & -- & 5 \\
\hline \multirow[t]{2}{*}{2004} & 9 & $M$ & 7 & -- & + & + & + & + & -- & 5 \\
\hline & 7 & $\mathrm{~F}$ & 8 & -- & + & N.D & -- & + & -- & 5 \\
\hline \multirow[t]{2}{*}{2005} & 37 & $M$ & 7 & - & + & -- & -- & + & -- & 5 \\
\hline & 10 & $F$ & 7 & -- & + & N.D & -- & + & -- & 5 \\
\hline \multirow[t]{2}{*}{2005} & 45 & $\mathrm{~F}$ & 8 & - & + & -- & + & + & -- & 7 \\
\hline & 51 & $M$ & 7 & -- & + & -- & + & + & -- & 7 \\
\hline \multirow[t]{2}{*}{2005} & 32 & F & 8 & -- & + & -- & + & -- & -- & 8 \\
\hline & 64 & $M$ & 8 & + & -- & -- & + & -- & -- & 8 \\
\hline \multirow[t]{2}{*}{2007} & 18 & F & 10 & -- & + & N.D & + & -- & -- & 9 \\
\hline & 42 & F & 9 & -- & + & N.D & + & -- & -- & 9 \\
\hline 2008 & 45 & $M$ & 6 & N.D & + & + & + & + & -- & 10 \\
\hline
\end{tabular}


Table 149 Cases of familial summer type hypersensitivity pneumonitis reported in Japan (Continued)

\begin{tabular}{|c|c|c|c|c|c|c|c|c|c|c|}
\hline & 43 & $F$ & 6 & N.D & + & -- & + & + & -- & 10 \\
\hline \multirow[t]{2}{*}{2009} & 74 & $M$ & 8 & + & + & + & -- & -- & + & 11 \\
\hline & 53 & $F$ & 7 & + & + & -- & -- & -- & + & 11 \\
\hline \multirow[t]{2}{*}{2012} & 58 & $\mathrm{~F}$ & 7 & + & + & + & + & -- & + & Our case \\
\hline & 63 & $M$ & 7 & + & + & + & - & -- & + & Our case \\
\hline
\end{tabular}

N.D not determined.

We conducted environmental research at the two patients' house. Tatami mats (a floor fitting made of straw that are peculiar to Japan) were present and were noted to be crumbled and in a decaying state (Figure $2 \mathrm{~A}$ ). Beneath the tatami mats, numerous white-colored and malodorous particulates were recognized and culture of this material showed multiple soft nodules of white piedra on Sabouraud agar, suggestive of Trichosporon asahii (Figure 2B). Those white colonies produced blue colored hyphae that disarticulated into rectangular arthroconidia with rounded ends (Figure $2 \mathrm{C}$ ) on light microscopy, measuring approximately $5 \mu \mathrm{m}$ (Figure 2D) on electron microscopy. Further analysis on slide agglutination tests using Trichosporon antigen (type II; known as T. asahii) and serum from the two patients showed a positive anti-T. asahii titer (2X). Further, the agglutination test using the strain of $T$. asahiii isolated from their house (Figure 2) showed a positive result for anti-T. asahii titer both in the husband (4X) and in the wife (8X).
Fungal deoxyribonucleic acid (DNA) was extracted using the method of Makimura et al. [2] and the intergenic spacer (IGS) 1 region was sequenced according to the method of Sugita et al. [3]. Briefly, the Trichosporon IGS 1 region (approximately $500 \mathrm{bp}$ ) was amplified by polymerase chain reaction (PCR) using the oligonucleotide primers 26SF (5ÅL-ATCCTTTGCAGA CGACTTGA-3ÅL) and 5SR (5ÅL-AGCTTGACTTCGC AGATCGG-3ÅL). The PCR products were sequenced with 26SF and 5SR using an ABI 3700 DNA sequencer with an ABI PRISM BigDye Terminator Cycle Sequencing kit (Applied Biosystems, CA, USA), according to the manufacturer's instructions. Based on these methods, the white colonies on Sabouraud agar identified as T. asahii.

Using the PubMed database, we identified and reviewed 22 studies with a total of 49 patients (including the two present cases) of family occurrence of SHP in Japan (Table 1) [4-10]. The mean age of affected patients
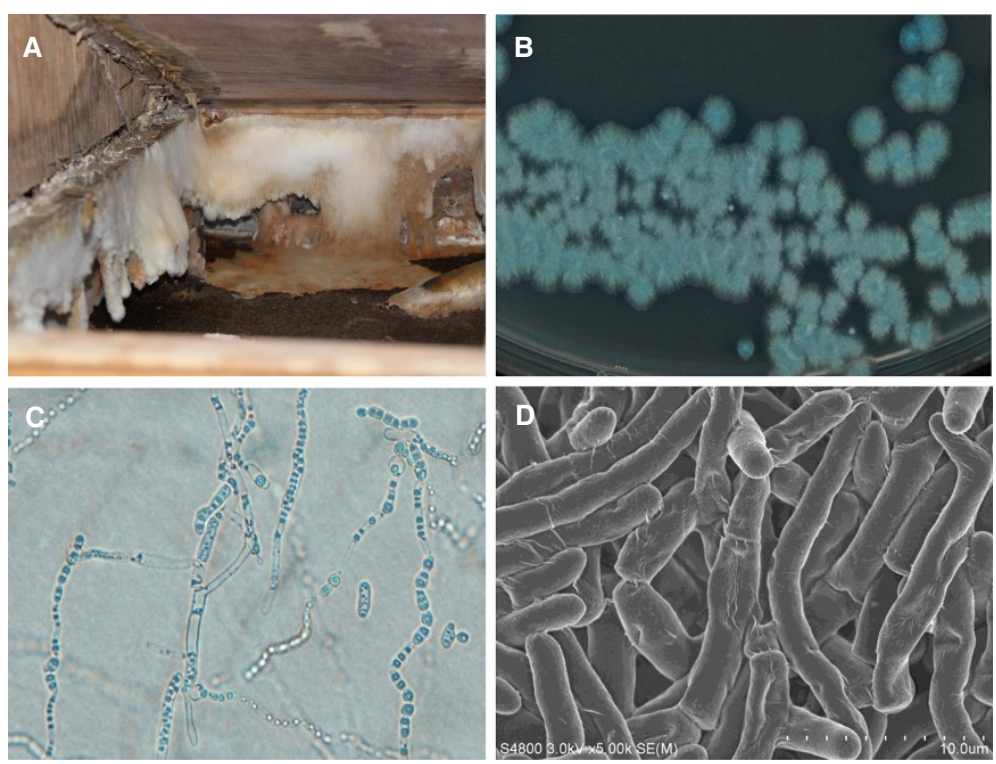

Figure 2 Environmental research at the patient's home and multidisciplinal identification for Trichosporon asahii. Environmental research at the patients' home showed tatami mats that were crumbled and in a decaying state with malodorous white matters beneath the mats (Panel A). On Sabouraud agar, multiple soft nodules of white piedra are cultured, suggesting Trichisporon asahii (Panel B). Light microscopy demonstrates the blue colored hyphae that disarticulate into rectangular arthroconidia with rounded ends (Panel C). Electron microscopy clearly depicts those rounded ends with size up to $5 \mu \mathrm{m}$ (Panel D). 
was $36.1 \pm 15.9$ (mean \pm SD [SD: standard deviation]), the age range was from 2 to 74 years, and the male to female ratio was 22:27. Among the 49 patients, 20 patients were married couples, and the other 20 patients had blood relationships. Among the 49 patients, the number of smokers and non-smokers was 13 and 22, respectively. Information regarding smoking history was not obtained in the other 14 patients. Thirty-five patients were assessed for specific anti-Trichosporon spp. antibody, of whom 31 patients (88.5\%) had positive results. The presence of acute respiratory failure (defined as oxygen saturation of less than 90\%) was observed in 22 patients with SHP (44.9\%). HLA phenotyping was assessed in 11 studies (data not shown), and the present two cases described SHP-sensitive HLA phenotypes in both the husband (A2) and the wife (A11, DQ8). The geographic distribution of the 49 cases of Japanese SHP showed a predilection for the western and southern parts of the country, and the condition was more common in prefectures bordering the Pacific Ocean than in those facing the Sea of Japan (Figure 3). The most northernmost case of the disease was in Saitama Prefecture, located at a latitude of $36^{\circ} \mathrm{C}$ north, and the area with the most cases (six studies; 13 patients) was the Kanto plain (Saitama and Kanagawa Prefectures and Tokyo area). Based on the annual records of the Japan Meteorological Agency, the average temperature and humidity at the time of onset in individual cases was $25.9^{\circ} \mathrm{C} \pm 2.2$ (mean \pm SD.) and $74.1 \% \pm 4.1$ (mean \pm SD.), respectively. Ninety percent of all cases of familial SHP in this study occurred from July to September, which corresponds to the after rainy season with high temperature and/or high humidity in Japan.

Review of the 49 cases shows the following management strategies: oral prednisolone only $(n=20,43.5 \%)$, avoidance of fungal exposure and house cleaning $(\mathrm{n}=11,22.4 \%)$, moving to a new house $(\mathrm{n}=10,20.4 \%)$, moving to a new house and oral prednisolone $(n=6$, $12.2 \%)$, and unknown $(\mathrm{n}=2,4.1 \%)$. Eleven patients (22.4\%) experienced recurrence, all of whom stayed in the house without moving. No recurrence was noted in patients who moved to a new house.

\section{Discussion}

Summer-type HP (SHP) is a form of HP caused by inhalation of Trichosporon asahii or mucoides during a hot and humid summer season. SHP accounts for three quarters of $\mathrm{HP}$ and has been reported in Japan since 1973 [1,11]. Familial SHP comprises 20 to $25 \%$ of cases of SHP [12-14], but no study has performed a review of the relevant literature so far. More than $90 \%$ of SHP patients had anti-Trichosporon antibodies or had a positive result for inhalation challenges of the antigen, as was seen in the present two cases. Review of the literature confirmed a geographic and climatic predilection for SHP depends on the environment, with the disease being more common according to an ambient temperature of $25-28^{\circ} \mathrm{C}$ and a relative humidity of $80 \%$ or more in the presence of damp wood [14], all of which represent better conditions for growth of Trichosporon spp.

Twenty three Families of Summer type Hypersensitivity Pneumonitis reported in Japan

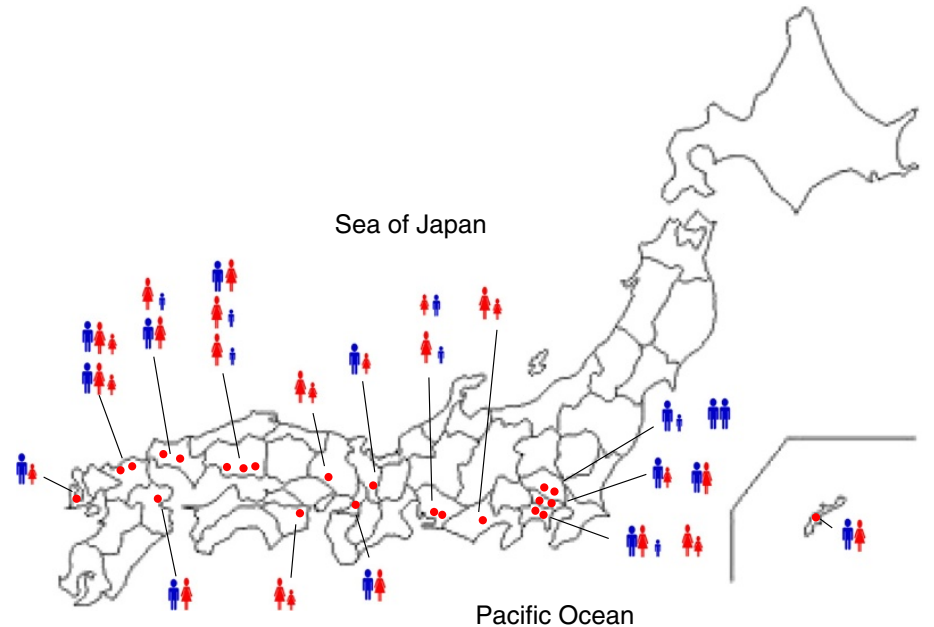

Figure 3 Geographic distribution of the $\mathbf{4 9}$ cases of Japanese summer type hypersensitivity pneumonitis (SHP). The disease is more common in the western and southern parts of the country and has a predilection for areas bordering the Pacific Ocean area when compared with areas facing the Sea of Japan. The northernmost site of the disease was in the Saitama Prefecture, located at a latitude of $36^{\circ}$ north. $\bullet$ indicates one SHP event. (blue human-shaped symbol) and (red human-shaped symbol) indicate male or female adult patients, respectively. (small blue human-shaped symbol) and (small red human- shaped symbol) indicate boy or girl patients who lived with their family. The map of Japan was obtained from the site (http://aoki2.si.gunma-u.ac.jp/map/map.html). 
Previous reports in Japan showed that HLA-DQw3 (DQ7, DQ8, DQ9) $[15,16]$ and HLA-A11, A2 or DR9 [16] were genetic factors associated with SHP, as was seen in the present two cases. In addition, the disease was more common in non-smokers than in smokers [17], which may account for our result that the number of non-smokers was larger than that of smokers. Thus, development of familial SHP required the presence of environmental and genetic factors, including smoking and exposure to a large amount of inhalation antigens.

SHP may occur in any type of house, and approximately half of familial SHP patients suffered from acute respiratory failure in this study. Trichosporonosis occurs in areas where the mean maximum temperature is higher than $25^{\circ} \mathrm{C}$ for 6 months or more. Furthermore, some cases of familial SHP were reported in Korea [18] or southern Africa [19] where the temperature is relatively hot $\left(>25^{\circ} \mathrm{C}\right)$ and the climate is humid $(\sim 80 \%)$, which suggests that some cases of SHP may be unrecognized and misdiagnosed as spontaneous pneumonia or other respiratory diseases. In this regard, a greater understanding the clinical, pathologic, and environmental features of SHP might help improve diagnosis and delivery of appropriate management for this condition.

\section{Conclusion}

Summer-type hypersensitivity pneumonitis may be unrecognized and misdiagnosed as pneumonia or other respiratory diseases. A greater understanding of the clinical, pathologic, and environmental features of summertype hypersensitivity pneumonitis might help improve diagnosis and delivery of appropriate management for this condition.

\section{Consent}

Written informed consent was obtained from the patient for publication of this Case Report and any accompanying images. A copy of the written consent is available for review by the Editor-in-Chief of this journal.

\section{Abbreviations}

SHP: Summer-type hypersensitivity pneumonitis.

\section{Competing interests}

The authors declare that they have no competing interests.

\section{Authors' contributions}

AN and TS drafted the initial manuscript and modified it in reference to the other. HT and HG edited the manuscript. AN, TS, and TW were involved in diagnostics and treatment of the patient. MF analyzed pathological findings. TM, IR, and TS contributed to all laboratory examinations. All authors read and approved the final manuscript.

\section{Author details}

${ }^{1}$ Department of Respiratory Medicine, Kyorin University School of Medicine, 6-20-2 Shinkawa, 181-8611, Mitaka City, Tokyo, Japan. Division of Hematology, Department of Internal Medicine, Juntendo University School of
Medicine, 2-1-1 Hongou, 113-8421, Bunkyo ward, Tokyo, Japan. ${ }^{3}$ Department of Microbiology, Meiji Pharmaceutical Universitys, 2-522-1 Noshio, 204-0004, Kiyose city, Tokyo, Japan. ${ }^{4}$ Department of Pathology, Kyorin University School of Medicine, 6-20-2 Shinkawa, 181-8611, Mitaka City, Tokyo, Japan.

Received: 27 March 2013 Accepted: 10 September 2013 Published: 13 September 2013

\section{References}

1. Ando M, Arima K, Yoneda R, Tamura M: Japanese summer-type hypersensitivity pneumonitis. Geographic distribution, home environment, and clinical characteristics of 621 cases. Am Rev Respir Dis 1991, 144(4):765-769.

2. Makimura K, Murayama SY, Yamaguchi H: Detection of a wide range of medically important fungi by the polymerase chain reaction. J Med Microbiol 1994, 40(5):358-364

3. Sugita T, Nakajima M, Ikeda R, Matsushima T, Shinoda T: Sequence analysis of the ribosomal DNA intergenic spacer 1 regions of Trichosporon species. J Clin Microbiol 2002, 40(5):1826-1830.

4. Sugiyama K, Mukae H, Ishii H, Ide M, Ishimoto H, Kakugawa T, Hisatomi K, Nakayama S, Shirai R, Miyazaki Y, et al: [Familial summer-type hypersensitivity pneumonitis--case report and review of literature]. Nihon Kokyuki Gakkai Zasshi 2005, 43(11):683-688.

5. Tanaka N, Taooka Y, Fujitaka K, Sakamoto N: [Trichosporon antibodies (corrected of antigen) and HLA-antigen in summer-type hypersensitivity pneumonitis in a family]. Nihon Kokyuki Gakkai Zasshi 2005, 43(12):741-745.

6. Makinodan K, Yoshikawa M, Fukuoka A, Yoshimoto E, Tamaki S, Tomoda K Hamada K, Kimura H: [A familial case of summer-type hypersensitivity pneumonitis possibly associated with bird breeder's lung diagnosed by bronchoalveolar lavage fluid]. Nihon Kokyuki Gakkai Zasshi 2005, 43(11):693-699.

7. Ono E, Maeda Y, Mori A, Tanimoto H, Fukutomi Y, Oshikawa C, Sekiya K, Thuburai T, Thurikisawa N, Otomo M, et al: [Summer-type hypersensitivity pneumonitis-immunological examinations in onset and non-onset members]. Nihon Kokyuki Gakkai Zasshi 2007, 45(7):566-571.

8. Amemiya $Y$, Shirai R, Ando S, Fujii H, Iwata A, Kai N, Otani S, Umeki K, Ishii H, Kadota J: [Familial summer-type hypersensitivity pneumonitis in a husband and wife]. Arerugi 2008, 57(11):1182-1187.

9. Koike K, Sekiya M, Yae T, Mori T, Suzuki T, Seyama K, Otani Y, Yoshizawa Y, Uekusa T, Takahashi K: [Two cases of familial summertype hypersensitivity pneumonitis requiring differentiation from bird breeder's lung]. Nihon Kokyuki Gakkai Zasshi 2009, 47(10):947-952

10. Ubukata M, Takayanagi N, Matsushima H, Sakamoto T, Motegi M, Yanagisawa T, Sugita Y, Kawabata Y, Kanazawa M: [Familial summertype hypersensitivity pneumonitis in a grandfather and his two-anda-half-year-old grandson]. Nihon Kokyuki Gakkai Zasshi 2000, 38(12):923-927.

11. Kawai T, Tamura M, Murao M: Summer-type hypersensitivity pneumonitis. A unique disease in Japan. Chest 1984, 85(3):311-317.

12. Ando M, Konishi K, Yoneda R, Tamura M: Difference in the phenotypes of bronchoalveolar lavage lymphocytes in patients with summer-type hypersensitivity pneumonitis, farmer's lung, ventilation pneumonitis, and bird fancier's lung: report of a nationwide epidemiologic study in Japan. J Allergy Clin Immunol 1991, 87(5):1002-1009.

13. Yoshida K, Suga M, Nishiura Y, Arima K, Yoneda R, Tamura M, Ando M: Occupational hypersensitivity pneumonitis in Japan: data on a nationwide epidemiological study. Occup Environ Med 1995, 52(9):570-574

14. Ando $M$, Suga $M$, Nishiura $Y$, Miyajima M: Summer-type hypersensitivity pneumonitis. Intern Med 1995, 34(8):707-712.

15. Mimura S, Kobayashi H, Kanoh S, Motoyoshi K, Aida S: [Summer-type hypersensitivity pneumonitis in monozygotic twins]. Nihon Kokyuki Gakkai Zasshi 2003, 41(2):133-137.

16. Makimoto N, Kajimoto K, Inoki A, Irie S, Naniwa J, Fujita T, Ueno K, Shiraishi T, Tada S, Kimura I: [Familial outbreak with hypersensitivity pneumonitis]. Nippon Naika Gakkai Zasshi 1991, 80(7):1132-1133.

17. Arima K, Ando M, Ito K, Sakata T, Yamaguchi T, Araki S, Futatsuka M: Effect of cigarette smoking on prevalence of summer-type hypersensitivity 
pneumonitis caused by Trichosporon cutaneum. Arch Environ Health 1992, 47(4):274-278.

18. Yoo CG, Kim YW, Han SK, Nakagawa K, Suga M, Nishiura Y, Ando M, Shim YS: Summer-type hypersensitivity pneumonitis outside Japan: a case report and the state of the art. Respirology 1997, 2(1):75-77.

19. Swingler GH: Summer-type hypersensitivity pneumonitis in southern Africa. A report of 5 cases in one family. S Afr Med J 1990, 77(2):104-107.

doi:10.1186/1756-0500-6-371

Cite this article as: Nakajima et al: Familial summer-type hypersensitivity pneumonitis in Japan: two case reports and review of the literature. BMC Research Notes 2013 6:371.

\section{Submit your next manuscript to BioMed Central and take full advantage of:}

- Convenient online submission

- Thorough peer review

- No space constraints or color figure charges

- Immediate publication on acceptance

- Inclusion in PubMed, CAS, Scopus and Google Scholar

- Research which is freely available for redistribution 